\title{
Integration of Marine Macroalgae (Chaetomorpha maxima) with a Moving Bed Bioreactor for Nutrient Removal from Maricultural Wastewater
}

\author{
Xian Li $\mathbb{D}^{1,2,3}$ Yale Deng, ${ }^{4}$ Xueying Li, ${ }^{1,2,3}$ Xiaona Ma $\mathbb{D}^{1,2,3}$ Jinxia Wang $\mathbb{D}^{1,2,3}$ \\ and Jun $\mathrm{Li}^{1,2,3}$ \\ ${ }^{1}$ Key Laboratory of Experimental Marine Biology, Institute of Oceanology, Chinese Academy of Sciences, Qingdao 266071, China \\ ${ }^{2}$ Laboratory for Marine Biology and Biotechnology, Qingdao National Laboratory for Marine Science and Technology, \\ Qingdao 266071, China \\ ${ }^{3}$ Center for Ocean Mega-Science, Chinese Academy of Sciences, Qingdao 266071, China \\ ${ }^{4}$ Aquaculture and Fisheries Group, Department of Animal Sciences, Wageningen University, Wageningen 6708, Netherlands
}

Correspondence should be addressed to Xiaona Ma; marianna_iocas@163.com and Jinxia Wang; jxwang@qdio.as.cn

Received 16 April 2020; Revised 18 May 2020; Accepted 26 May 2020; Published 23 June 2020

Academic Editor: Jin Li

Copyright (C) 2020 Xian Li et al. This is an open access article distributed under the Creative Commons Attribution License, which permits unrestricted use, distribution, and reproduction in any medium, provided the original work is properly cited.

Rather than direct nutrient removal from wastewaters, an alternative approach aimed at nutrient recovery from aquacultural wastewaters could enable sustainable management for aquaculture production. This study demonstrated the feasibility of cultivating marine macroalgae (Chaetomorpha maxima) with a moving bed bioreactor (MBBR-MA), to remove nitrogen and phosphorus in aquaculture wastewater as well as to produce macroalgae biomass. MBBR-MA significantly increased the simultaneous removal of nitrate and phosphate in comparison with only MBBR, resulting in an average total nitrogen (TN) and total phosphorus (TP) removal efficiency of $42.8 \pm 5.5 \%$ and $83.7 \pm 7.7 \%$, respectively, in MBBR-MA while MBBR had no capacity for TN and TP removal. No chemical oxygen demand (COD) removal was detected in both reactors. Phosphorus could be a limiting factor for nitrogen uptake when $\mathrm{N}: \mathrm{P}$ ratio increased. The recovered nitrogen and phosphorus resulted in a specific growth rate of $3.86 \%-10.35 \%$ /day for C. maxima with an uptake $\mathrm{N}: \mathrm{P}$ ratio of 6 . The presence of macroalgae changed the microbial community in both the biofilter and water by decreasing the relative abundance of Proteobacteria and Nitrospirae and increasing the abundance of Bacteroidetes. These findings indicate that the integration of the macroalgae C. maxima with MBBR could represent an effective wastewater treatment option, especially for marine recirculating aquaculture systems.

\section{Introduction}

Nitrogen and phosphorus removal from wastewater in aquaculture production systems is crucial to reduce the eutrophication of receiving water and to ensure the sustainable development of the industry. The limited availability of land and water resources is restricting the further expansion of aquaculture. There has been growing interest in the development of intensive land-based marine aquaculture, especially recirculating aquaculture systems (RASs), in which water can be reused after a series of treatment processes [1]. A biofilter is the core water treatment unit in an RAS, in which ammonia, as the most toxic form of nitrogen, is converted to nitrite by ammonia-oxidizing bacteria $(\mathrm{AOB})$ and then further converted by nitrite-oxidizing bacteria (NOB) to nitrate [2]. A moving bed biological filter (MBBR) is widely used in RASs due to its advantageous properties, including sufficient mixing, effective mass transfer, high removal rate of pollutants, and relatively small spatial requirements [3]. However, the nitrate and phosphorus concentration tends to accumulate to a high value in an MBBR system, and nitrate even could reach hundreds of $\mathrm{mg} / \mathrm{L}$ [4-6]. It has been shown that high nitrate concentrations can also pose a potential 
hazard to the cultured species [7-9]. Without proper treatment, the nitrate and phosphorus discharged in the saline wastewater can lead to eutrophication of the adjacent ecosystems [10].

Biological denitrification that converts nitrate and nitrite to nitrogen gas has been applied in RASs [11]; however, this process faces operational challenges, such as the requirement for a large carbon input, technical management, and nitrous oxide emissions $[12,13]$. Moreover, eliminating nitrate from the system through nitrogen gas reduces the nutrient recovery efficiency from wastewater. Phosphorus is considered a growth-limiting nutrient in many water systems, which could be removed by plants, microorganism, and chemicals, while no effective approaches have been developed in RAS for phosphorus, especially dissolved phosphorus elimination. Yogev et al. [14] combined denitrification with anaerobic digestion to recover phosphorus by its sustainable reuse as a fertilizer for plants in fresh RAS. Macroalgae have been used for water purification due to their high nitrogen and phosphate removal efficiencies, which make them suitable for biomass production and as a resource for biofuel feedstocks $[15,16]$. The use of macroalgae could significantly reduce the harvesting and dewatering costs compared with microalgae due to their larger size and tendency to grow as dense floating mats or substrate-attached turfs [17]. Macroalgae are usually used in integrated multitrophic aquaculture (IMTA) systems to maintain water quality and to serve as food for cultured species [18]. Bambaranda et al. [19] tried to use Caulerpa lentillifera as a bioremediatory species instead of MBBR for nutrient removal in a RAS where a huge volume of macroalgae was needed to achieve the required high efficacy. However, no studies have investigated the feasibility of incorporating macroalgae with an MBBR within marine wastewater treatment.

Nambiar and Bokil [20] proposed the concept of a microalgae-bacteria consortia to study the uptake of nitrogen, and several researches were carried to study the interactions of microalgae and bacteria [21]. Both macroalgae and microalgae have numerous effects on microbial community structure and aquatic organisms by directly altering water nutrients, moderating hydrological conductivity, transporting oxygen through their bodies, and secreting chemicals as catalysts $[22,23]$. Some bacteria and algae in the system have a mutually beneficial relationship, through which bacteria can convert ammonia into nitrite or nitrate, which can be utilized by algae, while the algae produce oxygen and organic matter for the growth of bacteria. Compared with the traditional single-step treatment, the nitrogen removal efficiency in aquaculture water can be improved by exploiting the synergistic effect that occurs among multiple species [24].

Chaetomorpha maxima, which is known for its blooming nature as well as its tolerance to fluctuating aquarium conditions, is a suitable marine macroalgae (MA) species for aquaculture wastewater nutrient recovery and biomass production [25]. And in our preliminary study, Chaetomorpha maxima is a good feed candidate for sea cucumber. In this study, integrated MBBR-MA (Chaetomorpha maxima) circulating systems were built to evaluate the nitrogen and phosphorus removal performance as well as macroalgae bio- mass production by comparing them with MBBRs with no macroalgae culture. How the inclusion of macroalgae influenced the microbial community composition in both water bodies and the packed biofilters was also analyzed. This study provides the basis for the application of the MBBR-MA system, which could reduce nutrient accumulations in aquaculture wastewater and improve the sustainability of aquaculture production system.

\section{Materials and Methods}

2.1. Experimental Setup and Operational Procedure. A schematic of the integrated recirculating MBBR-MA system is shown in Figure 1. The MBBR-MA system included a $20 \mathrm{~L}$ water storage tank, two $3.5 \mathrm{~L}$ MBBRs, and a $150 \mathrm{~L}$ upflow algae reactor. The laboratory-scale MBBR was packed with ring plastic suspension filler (64 holes) to a filling rate of $30 \%$. The MBBR was covered by the blackout cloth to avoid light. The water in the storage tank was lifted by a submerged pump to the MBBR and then to the algae reactor and finally flowed back to the storage tank. An underwater light at 15000 lx light intensity was set in the algae reactor, and the ratio of red to white light was $1: 3$.

Three replicates of two treatments, MBBR-MA and MBBR, were used to test the nutrient removal performance. At the start of the experiment, $50 \mathrm{~g}$ of MA (Chaetomorpha maxima) was stocked in each of the three algal reactors in the MBBR-MA treatment, while no MA was stocked in the MBBR treatment. The systems were fed with simulated maricultural wastewater prepared using fermented Atlantic salmon residual excrement [26]. The residual excrement was dried at $105^{\circ} \mathrm{C}$ for $48 \mathrm{~h}$ and then broken into a powder and mixed with seawater. A solution of the mixture was anaerobically fermented in a sealed container for $5 \mathrm{~d}$ before use. The influent wastewater quality was adjusted as follows: $\mathrm{NH}_{4}{ }^{+}-\mathrm{N}, 2.0 \pm 0.5 \mathrm{mg} / \mathrm{L} ; \mathrm{NO}_{2}{ }^{-}-\mathrm{N}, 0.1 \pm 0.05 \mathrm{mg} / \mathrm{L} ; \mathrm{NO}_{3}{ }^{-} \mathrm{N}$, $2.0 \pm 0.5 \mathrm{mg} / \mathrm{L} ; \quad \mathrm{PO}_{4}{ }^{3-}-\mathrm{P}, \quad 0.2 \pm 0.5 \mathrm{mg} / \mathrm{L} ;$ total $\mathrm{P}, 0.3 \pm$ $0.05 \mathrm{mg} / \mathrm{L}$; chemical oxygen demand (COD), $3.00 \pm 0.5$ $\mathrm{mg} / \mathrm{L}$, and Salinity, 31\%o. Both systems were operated in recirculating mode at a rate of $7.5 \mathrm{~mL} / \mathrm{min}$ to achieve a hydraulic retention time (HRT) of $24 \mathrm{~h}$. The experiment lasted for $75 \mathrm{~d}$, consisting of 15 cycles, with each cycle operating for $4 \mathrm{~d}$, with an interval of $1 \mathrm{~d}$ to change the wastewater. The whole experimental period was divided into two stages, with stage I lasting for 10 cycles and stage II lasting for 5 cycles. Stage I was designed to evaluate nutrient removal efficiencies between MBBR-MA and MBBR. The fresh algae in the MBBR-MA systems were weighed after each cycle. Stage II was designed to verify whether the MBBR could recover after the removal of the algae reactor. After stage I, the algae in the MBBR-MA systems were removed. All the algae bioreactors were cleaned, and all the underwater lights were removed.

2.2. Water and Biofilm Collection. Water samples $(250 \mathrm{~mL})$ were taken from the water sample tape from the outlet of the algae bioreactor of all the six systems every $12 \mathrm{~h}$ for the analysis of total ammonia nitrogen (TAN), nitrite nitrogen $\left(\mathrm{NO}_{2}{ }^{-} \mathrm{N}\right)$, nitrate nitrogen $\left(\mathrm{NO}_{3}{ }^{-} \mathrm{N}\right)$, total nitrogen $(\mathrm{TN})$, total phosphorus (TP), and chemical oxygen demand 


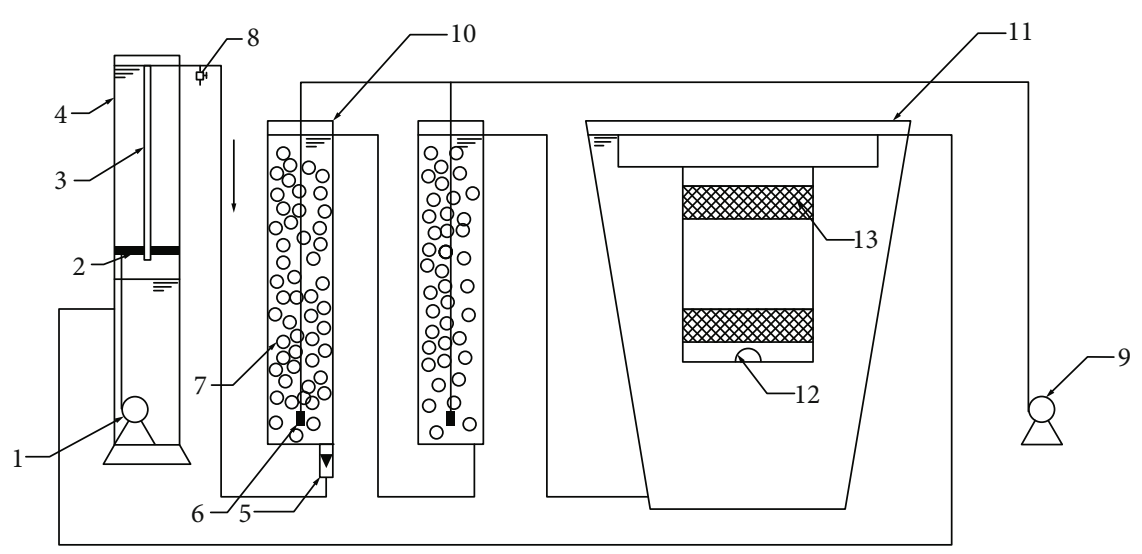

FIGURE 1: Schematic of the recirculating marine macroalgae with a moving bed bioreactor (MBBR-MA) system. 1, submerged pump; 2, baffle plate; 3 , overflow pipe; 4 , water storage tank; 5 , flowmeter; 6 , air stone; 7 , biofilm carrier; 8 , water sample tap; 9 , aeration pump; 10, moving bed biofilm reactor; 11 , algae bioreactor; 12 , underwater light; 13 , sieve.

(COD) according to standard methods [27]. All the water samples were stored at $4^{\circ} \mathrm{C}$ immediately after the collection and were analyzed for 12 hours. Microbial samples in both the biofilter and water were taken at the end of stage I (10 cycles) from the six systems. In detail, 15 plastic suspension fillers were randomly selected from each MBBR system. The biofilms attached to the fillers were collected by shaking in $30 \mathrm{~mL}$ of sterile seawater with $100 \mu \mathrm{L}$ of stabilizer (Tween 80 detergent solution) using a vortex mixer for $10 \mathrm{~min}$. Then, the solution was filtered through a $0.22 \mu \mathrm{m}$ polycarbonate filter (Millipore, Burlington, MA, USA) to collect the microorganisms. Similarly, $500 \mathrm{~mL}$ of water sampled from each system was filtered through a $0.22 \mu \mathrm{m}$ polycarbonate filter (Millipore, MA, USA) to collect the microorganisms in the water. All the processed samples were stored at $-80^{\circ} \mathrm{C}$ prior to DNA extraction.

2.3. DNA Extraction and High-Throughput Sequencing. The total DNA on the filter was extracted with an E.Z.N.A. ${ }^{\circledR}$ Water DNA Kit (Omega Bio-Tek, Norcross, GA, USA) according to the manufacturer's protocol. The DNA from the 12 microbial samples (six biofilm microbial samples and six water microbial samples) were profiled by polymerase chain reaction (PCR) amplification using 515F and 806R primers. The PCR products were separated by electrophoresis on $2 \%$ agarose gel, purified using a SanPrep DNA Gel Extraction Kit, and then quantified with NanoDrop. The purified mixtures were finally deep sequenced on the HiSeq2500 sequencing platform (Illumina, San Diego, CA, USA).

2.4. Processing of Sequencing Data. Raw data from the HiSeq2500 sequencing platform was processed with Cutadapt and the UCHIME algorithm to obtain clean reads [28, 29]. The clean reads without chimeras were clustered into operational taxonomic units (OTUs) at $97 \%$ similarity with UPARSE [30]. Representative sequences processed with QIIME 1.9.1 were used for taxonomic assignments based on the SILVA [31] and SSUrRNA databases [32]. Alpha diversity index values (Chaol richness estimator, Shannon index, and Simpson index) were obtained using the QIIME
1.9.1 package. A hierarchical cluster heat map was generated, and a principal coordinate analysis (PCoA) was performed based on weighted UniFrac distances of the detected OTUs, with the R package vegan.

2.5. Statistical Analyses. The specific growth rates (SGR, \%/d) of macroalgae were determined using the following formula:

$$
\operatorname{SGR}=\left[\left(\frac{W_{t}}{W_{0}}\right)^{1 / t}-1\right] \times 100 \%,
$$

where $W_{0}(\mathrm{~g})$ is the initial fresh weight, $W_{t}(\mathrm{~g})$ is the fresh weight at time $t$, and $t(\mathrm{~d})$ is the time interval.

The nitrogen, phosphorus, and COD removal efficiency (RE) was calculated using the following equation:

$$
\mathrm{RE}=\frac{C_{0}-C_{t}}{C_{0}} \times 100 \%
$$

where $C_{0}(\mathrm{mg} / \mathrm{L})$ and $C_{t}(\mathrm{mg} / \mathrm{L})$ are the nitrogen, phosphorus, or COD concentrations in the water at the start and after that each cycle, respectively.

Statistical analyses were performed using SPSS 20.0 software and included a Student $t$-test and one-way analysis of variance (ANOVA). Data was reported as the mean \pm standard deviation (SD). The data were subjected to a Student $t$-test. A $p$ value of $<0.05$ was considered statistically significant.

\section{Results and Discussion}

3.1. Long-Term Nitrogen and Phosphorus Removal Performance. The variation in the TAN, $\mathrm{NO}_{2}{ }^{-} \mathrm{N}, \mathrm{NO}_{3}{ }^{-}$ $\mathrm{N}$, and TP dynamics in both the MBBR-MA and MBBR systems is shown in Figure 2. The TAN concentrations at the start of each cycle were $2.02 \pm 0.10 \mathrm{mg} / \mathrm{L}$ and were reduced to $0.23 \pm 0.07$ (MBBR-MA) and $0.24 \pm 0.08$ (MBBR) $\mathrm{mg} / \mathrm{L}$ at the end of each cycle (Figure 2(a)). In stage I, TAN removal followed zero-order elimination kinetics in 


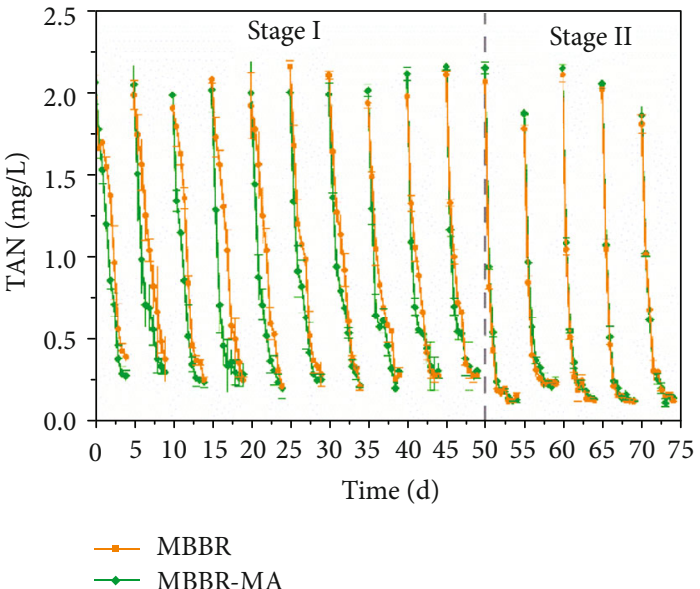

(a)

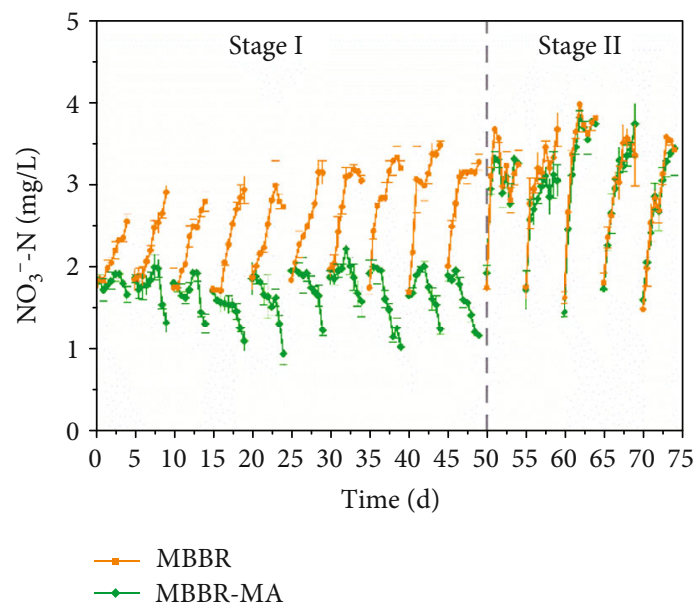

(c)

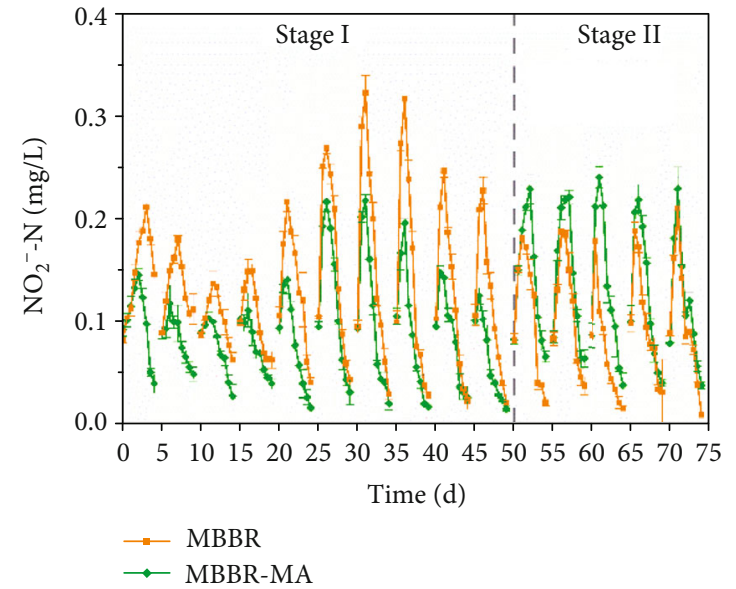

(b)

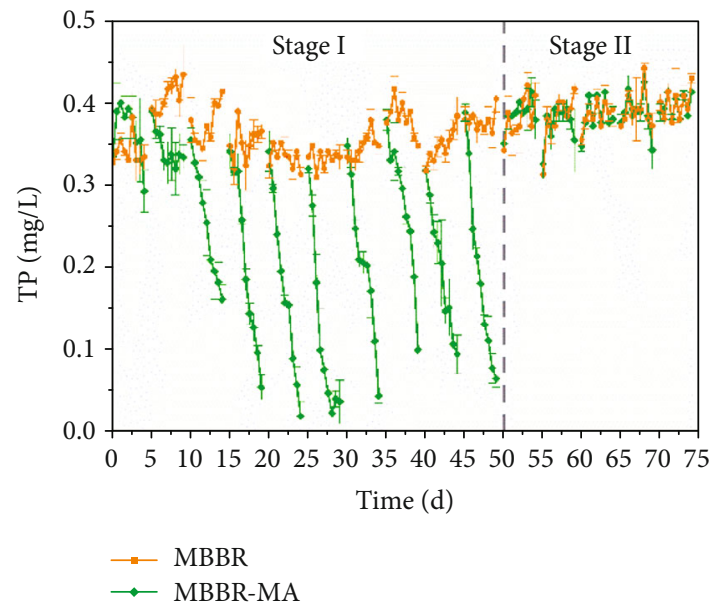

(d)

Figure 2: The concentrations of TAN (a), $\mathrm{NO}_{2}-\mathrm{N}(\mathrm{b}), \mathrm{NO}_{3}{ }^{-} \mathrm{N}(\mathrm{c})$, and $\mathrm{TP}$ (d) dynamics in both MBBA and MBBA-MA.

the MBBR system during the first four days of a cycle, while the MBBR-MA system had a higher TAN removal rate, indicating that MA contributed to TAN absorption, with the microorganisms in the MBBR playing the main role in TAN transformation. This result was in line with that of stage II, when MA was removed from the algae reactor in the MBBR-MA system, with no difference detected in TAN elimination in both systems.

Nitrite, as an intermediate product of nitrification, accumulated to a peak of $0.22 \pm 0.06 \mathrm{mg} / \mathrm{L}$ during the first two days and was further oxidized to nitrate in the MBBR system (Figure 2(b)). During stage I, the nitrite accumulation in the MBBR system was significantly $(p<0.05)$ higher than that in the MBBR-MA system, which could be attributed to the nitrite and ammonia assimilation by MA and relatively lower ammonia concentration utilized by bacteria in the MBBR-MA system. Therefore, when the algae were removed from the MBBR-MA in stage II, the sudden increase in the TAN loading caused a slightly higher nitrite accumulation in the MBBR-MA than in the MBBR. The nitrification process resulted in a constant nitrate accumulation of an average of $3.25 \pm 0.37 \mathrm{mg} / \mathrm{L}$ in the MBBR (Figure 2(c)). On the other hand, the nitrate concentration decreased to $1.00 \pm 0.10 \mathrm{mg} / \mathrm{L}$ at the end of stage I in the MBBR-MA system (Figure 2(c)), which could be explained by the absorption of MA. Direct nitrate adsorption by MA played a significant role in the nitrate reduction, which was confirmed by Ge and Champagne [17]. When MA was removed from the algae reactor in the MBBR-MA system at stage II, nitrate accumulation reoccurred.

As expected, MBBR had no contribution to phosphorus removal (Figure 2(d)). The biological removal of phosphorus is based on the phosphate-accumulating organisms (PAOs) under anaerobic and aerobic or anoxic conditions through sludge recycling [33]. The aerobic process of MBBR cannot enrich PAOs in the biofilm, which causes phosphorus accumulation in the system. On the hand, TP was eliminated from $0.35 \mathrm{mg} / \mathrm{L}$ in the influent to $0.06 \mathrm{mg} / \mathrm{L}$ in effluent of the MBBR-MA system after the acclimation of marine macroalgae for three cycles. The high capacity of TP removal in MBBR-MA was attributed to the uptake of phosphorus compounds for photosynthesis of marine macroalgae [34]. In our study, the average initial influent $\mathrm{N}: \mathrm{P}$ ratio in 
MBBR-MA was 12.4 while the average uptake $\mathrm{N}: \mathrm{P}$ ratio of MA was 6.0 at day 4 during cycle 4 to cycle 10 in stage I. A previous study showed that $\mathrm{N}: \mathrm{P}$ ratios greater than 15 in a temperate region indicated phosphate limitation for several species of MA [35]. The higher $\mathrm{N}: \mathrm{P}$ ratio in wastewater influent than that in macroalgae uptake implied that phosphorus availability was a limiting factor for C. maxima growth, inhibiting the further uptake of nitrogen from aquaculture wastewater.

3.2. Nutrient Removal Efficiency within a Cycle. The nutrient removal efficiency over the four days within a cycle is shown in Figure 3. The TAN removal efficiency increased gradually from day one to day four in each cycle (Figure 3(a)). In stage $\mathrm{I}$, the average accumulating TAN removal efficiency was $54.9 \%$ (MBBR-MA) and $33.2 \%$ (MBBR) on the first day, $70.8 \%$ (MBBR-MA) and $53.8 \%$ (MBBR) on the second day, $84.1 \%$ (MBBR-MA) and $77.4 \%$ (MBBR) on the third day, and $86.9 \%$ (MBBR-MA) and $86.0 \%$ (MBBR) on the fourth day. It was reported by the fact that $C$. maxima prefers to absorb ammonia as nitrogen source than nitrate when ammonia concentration is higher than $1.5 \mathrm{mg} / \mathrm{L}$ and prefers to absorb nitrite and nitrate when ammonia dropped below $1.5 \mathrm{mg} / \mathrm{L}$ [25]. Those results indicated that MA only contributed to TAN removal in MBBR-MA mainly on the first day when the TAN concentration was higher than $1.0 \mathrm{mg} / \mathrm{L}$ (Figure 2(a)). However, the difference between the two groups became insignificant on $\mathrm{d} 4$, indicating that microorganisms attached to MBBR played a significant role in TAN transformation. This assumption can be verified in stage II that there was no significant $(p<0.05)$ difference between the two treatments in TAN removal efficiency when macroalgae was removed.

In an MBBR, nitrification is a major ammonia transformation process, by which ammonia is oxidized to nitrite and further oxidized to nitrate. In stage I, the accumulation of $\mathrm{NO}_{3}{ }^{-} \mathrm{N}$ was consistent with the degradation of TAN caused by the nitrification process in the MBBR which explained the zero removal of TN in MBBR (Figure 3(b)). The decrease of nitrate mainly started from $\mathrm{d} 2$ in MBBRMA (Figure 2(c)), implying that C. maxima first utilize ammonia as nitrogen source then switched to nitrate when ammonia was lower than approximate $1.0 \mathrm{mg} / \mathrm{L}$. Overall, the direct absorption of nitrogen by $C$. maxima contributed to the TN removal in the MBBR-MA, with an average removal efficiency of $42.8 \%$ for $\mathrm{TN}$, ranging from $34.4 \%$ to $54.3 \%$ at day 4 (Figure 3(b)). C. maxima exhibited higher removal efficiency in TP removal (average, 80.0\%) when compared with TN removal (Figure 3(c)). This indicated that the relatively low phosphorus availability in aquaculture wastewater limited the nitrogen uptake by MA. Nevertheless, since autotrophic macroalgae uptake no carbon from the wastewater (Figure 3(d)), the lower nitrate level in the MBBR-MA system may elevate the $\mathrm{C}: \mathrm{N}$ ratio that could facilitate the denitrification process, which could benefit the zero-exchange operation of RAS.

3.3. Characteristics of MA Growth. The algal growth was described as the weight gain and SGR of MA on a fresh weight basis (Table 1). The fresh weight increased and the rate of growth gradually accelerated over the course of the study. At the end of the tenth period, the fresh weight of MA was $564.03 \mathrm{~g}$, i.e., 11 times the original algae weight. These results confirmed that MA can use inorganic nitrogen for their growth, contributing to aquaculture water purification [36-38]. However, the growth performance of the macroalgae varied according to the species used for cultivation. For example, Ulva lactuca grown in a mixture of seawater and sewage effluent (40\%:60\%) had an SGR of 0.5\%/day [37]. In Brazil, a study of the growth and biofiltration capacity of the macroalgae Gracilaria birdiae in tank cultivation had an SGR of 3.6\%/day [38]. Our study revealed a significant growth performance, with the SGR varying from 3.86 to $10.35 \% /$ day, indicating that the application of C. maxima could be an optimal algae alternative when treating maricultural wastewater.

\subsection{Characteristics of Microbial Diversity in Water and Biofilter}

3.4.1. Alpha-Diversity Analysis. A total of 855,846 highquality $16 \mathrm{~S}$ rRNA gene sequence reads were obtained from the 12 biofilter and water samples. Each library contained $56,298-87,910$ reads that were normalized to 56,298 reads for the comparison of microbial community diversity between the MBBR-MA and MBBR systems (Table 2). Water samples had a significantly $(p<0.05)$ higher microbial richness than biofilter samples according to the OTU number and Chao1 index values, while the addition of macroalgae did not significantly $(p<0.05)$ change the microbial richness in biofilters. Moreover, the Shannon and Simpson indices indicated that MA did not significantly change the evenness of the microbial community in biofilter samples. The Simpson index was significantly higher in the water samples with algae than in those without algae. The results of the alpha diversity analysis showed that the microbial community richness and diversity were lower in the biofilm than in the water samples, particularly for the Shannon and Simpson index results $(p<005)$, which was in line with previous studies $[39,40]$.

3.4.2. Beta Diversity Analysis. The difference in microbial composition between systems was analyzed by the weighted UniFrac distance and presented as a PCoA plot (Figure 4). A clear separation between the biofilter and water samples was observed along PC1 axes, which accounted for $75.97 \%$ of the total changes in the bacterial community composition. Many aquatic microorganisms are capable of colonizing surfaces, leading to the formation of biofilms with specialized properties [39, 40]. Thus, in terms of diversity (Table 2) and composition, the bacterial community in the water and biofilters was clearly different, which reflected the different microbiota compositions attached to RAS biofilters compared to the free-living community in the water phase of aquaculture systems [41].

The samples could be separated between MBBR-MA and MBBR along PC2, which explained $14.81 \%$ of the total variation in the bacterial community composition. This result 


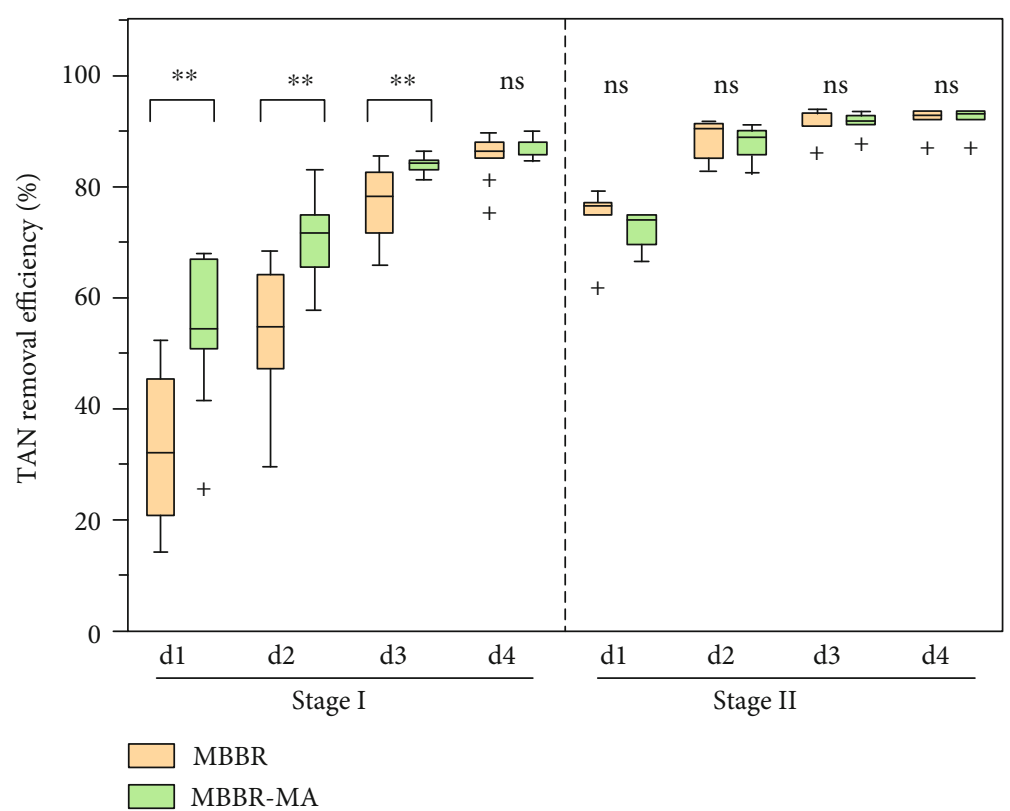

(a)

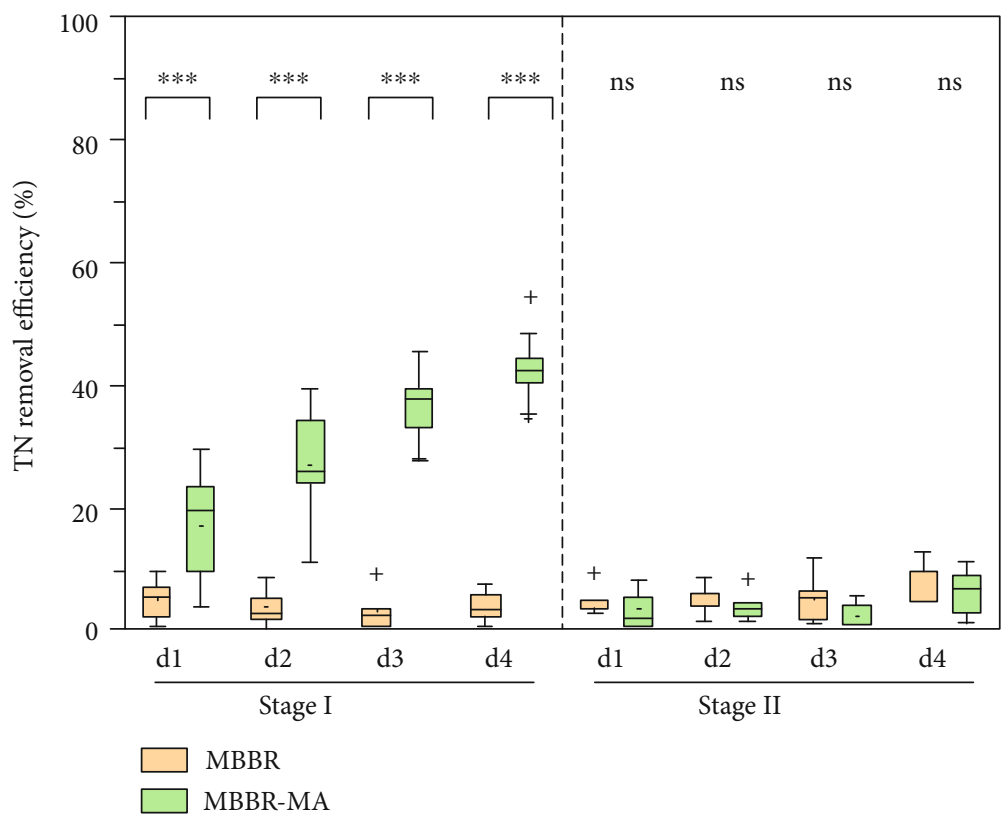

(b)

FIgUre 3: Continued. 


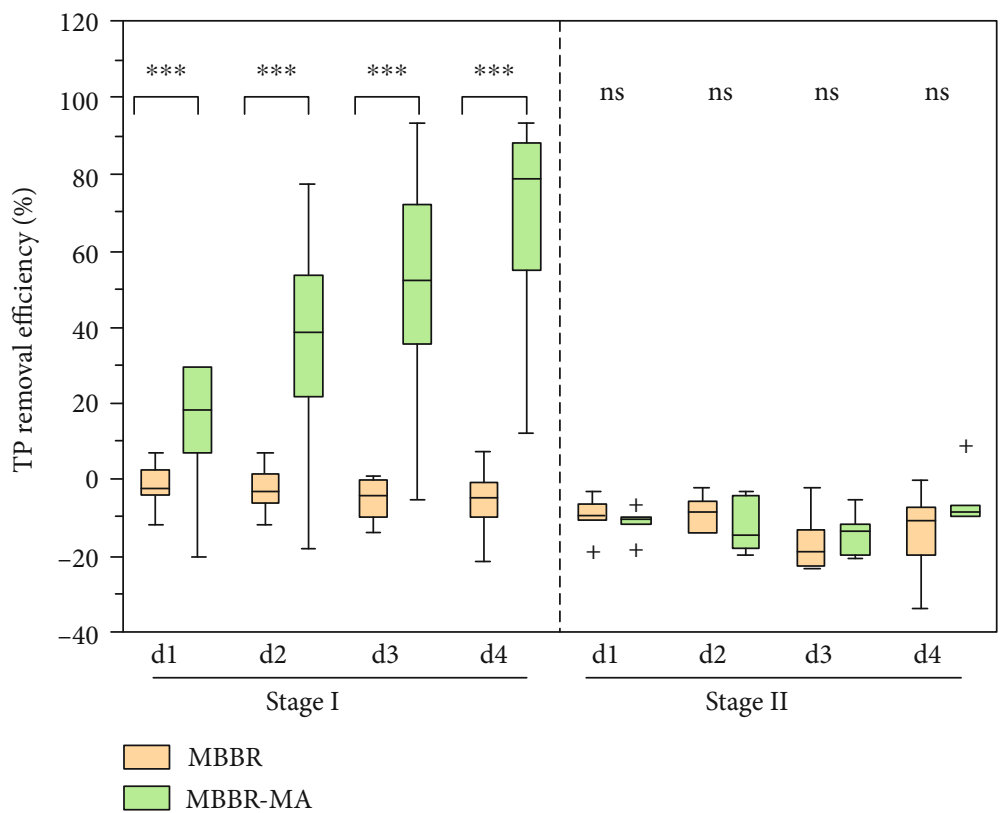

(c)

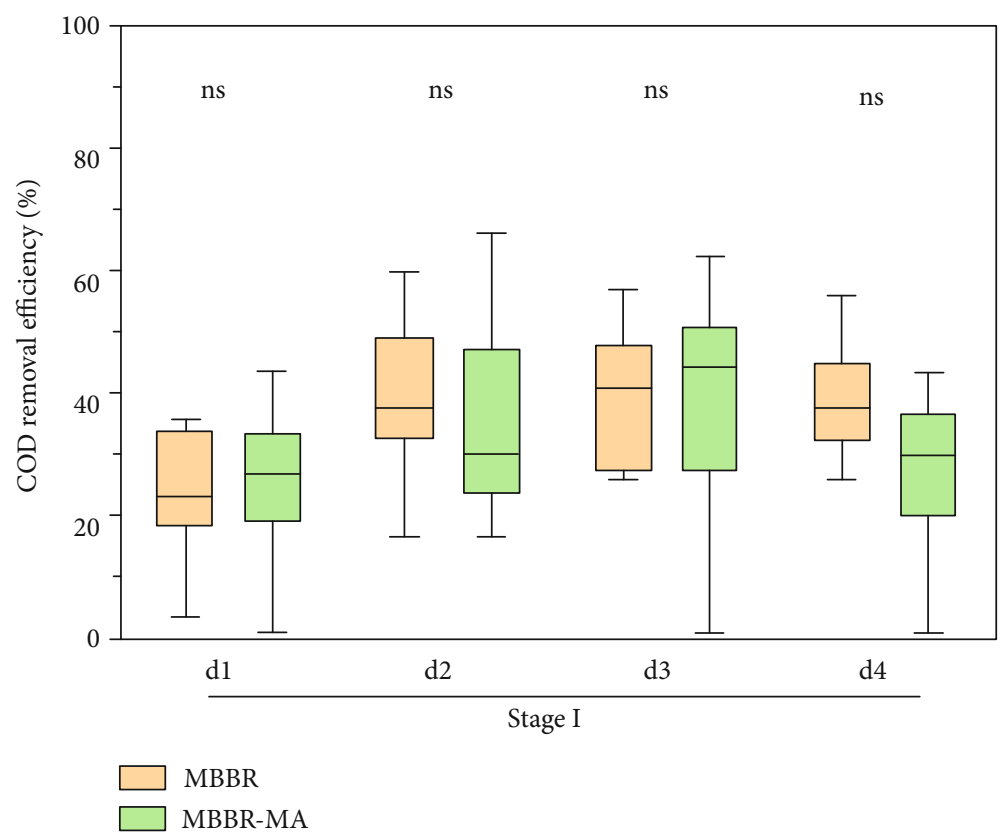

(d)

FIgure 3: The TAN (a), TN (b), TP (c), and COD (d) removal efficiency over the four days in stage I and stage II of both MBBR and MBBR-MA.

demonstrated that the microbial communities in both the biofilm and water samples were influenced by the presence of macroalgae. The MA induced a bigger shift in the microbial community in the water than in the biofilters. One reason for this was that the utilization of $\mathrm{CO}_{2}$ and release of oxygen during photosynthesis might change the $\mathrm{pH}$ in the water and further influence the microbial community composition $[42,43]$. Another possible reason could be that that the reduction in the nitrogen concentration by algae could also affect the microbial communities in MBBR, as suggested by previous studies $[7,44]$.
3.5. Microbial Community Composition. The microbial community composition of the biofilm and water samples was analyzed at phylum, class, and genus taxon levels (Figure 5). At the phylum level, the top 10 phyla were selected, and the remaining phyla were assigned to a cluster named "the others" (Figure 5(a)). The results showed that Proteobacteria (average relative abundance (RA), 63.4\%) was the most abundant phylum across all the samples, followed by Bacteroidetes (average RA, 22.4\%), which was also found with a high abundance in other marine MBBRs [45-47]. The integration of MA with MBBR significantly 


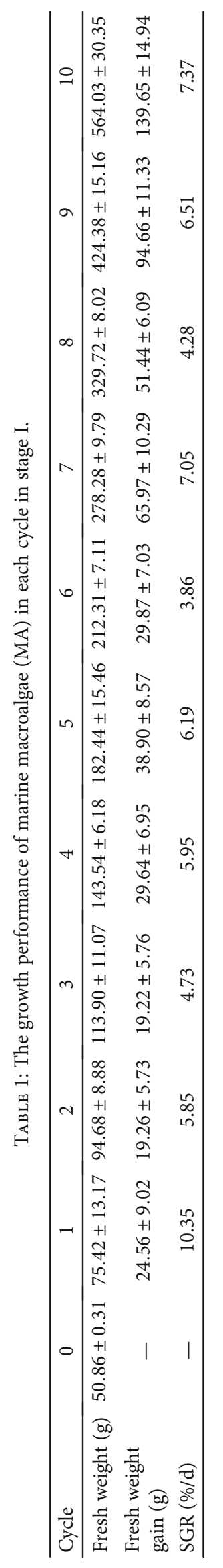


TABLE 2: Alpha-diversity indices of the biofilter and water samples from both MBBR and MBBR-MA.

\begin{tabular}{lcccccc}
\hline Sample name $(n=3)$ & ACE & Chao1 & Shannon & Simpson & PD whole tree \\
\hline \multirow{2}{*}{ Biofilter } & MBBR-MA & $900^{\mathrm{a}}$ & $901^{\mathrm{a}}$ & $6.10^{\mathrm{a}}$ & $0.96^{\mathrm{a}}$ & $76.73^{\mathrm{a}}$ \\
& MBBR & $844^{\mathrm{a}}$ & $840^{\mathrm{a}}$ & $6.25^{\mathrm{a}}$ & $0.97^{\mathrm{a}}$ & $77.63^{\mathrm{a}}$ \\
\hline \multirow{2}{*}{ Water } & MBBR-MA & $1094^{\mathrm{b}}$ & $1096^{\mathrm{b}}$ & $6.67^{\mathrm{b}}$ & $0.96^{\mathrm{a}}$ & $101.84^{\mathrm{b}}$ \\
& MBBR & $1194^{\mathrm{b}}$ & $1183^{\mathrm{b}}$ & $6.70^{\mathrm{b}}$ & $0.94^{\mathrm{b}}$ & $112.17^{\mathrm{b}}$ \\
\hline
\end{tabular}

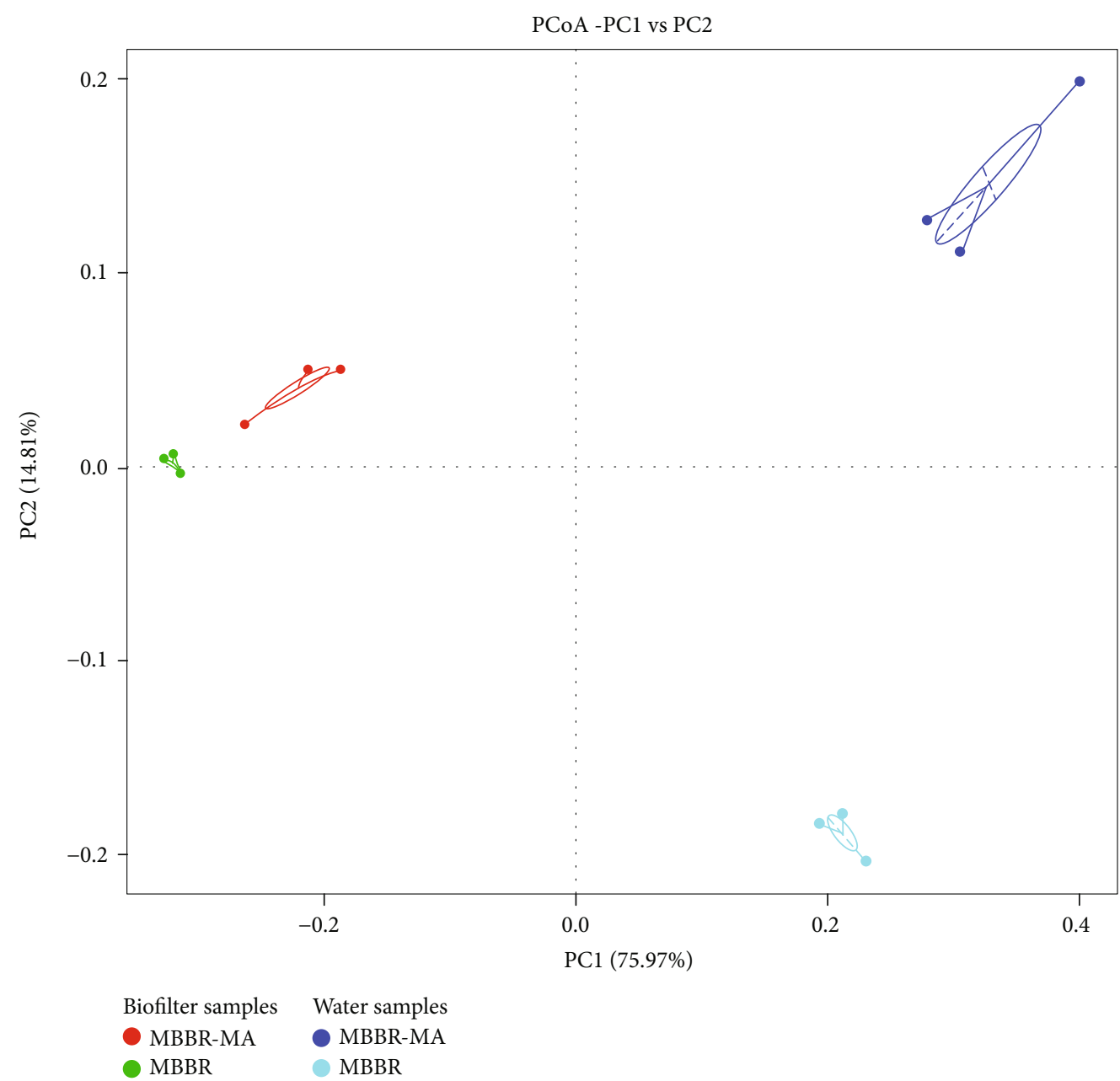

FIGURE 4: The microbial community distribution in both biofilter and water samples according to a principal coordinate analysis (PCoA) plot of MBBR and MBBR-MA.

decreased the RA of Proteobacteria and Nitrospirae and significantly increased the RA of Bacteroidetes in both biofilter and water samples. Nitrospirae is the dominant NOB in wastewater treatment systems [48], and many Bacteroidetes species have been reported to have the capacity for organic carbon degradation [49]. The relatively lower abundance of Nitrospirae in MBBR-MA biofilter samples could be explained by the relatively lower nitrite concentration detected in the MBBR-MA system (Figure 2(b)), because macroalgae also contribute to ammonia and nitrite removal. On the other hand, macroalgae may also enhance the growth of heterotrophic bacteria by producing organic compounds.
A heat map of the 35 most abundant genus-level taxa is shown in Figure 5(b). A clear separation between biofilter and water samples was observed. In the biofilter samples, Halomonas, Leisingera, Pseudoalteromonas, unidentified_ Gracilibacteria, Alteromonas, Vibrio, and Kordia were the most abundant genera in both treatments. Among them, macroalgae significantly $(p<0.05)$ increased the RA of unidentified Gracilibacteria and Kordia in the MBBR-MA compared with the MBBR. According to Chen et al. [50], genera belonging to Gracilibacteria can participate in the denitrification process and have nitrate removal abilities. According to Paul and Pohnert [51], Kordia, as algicidal 


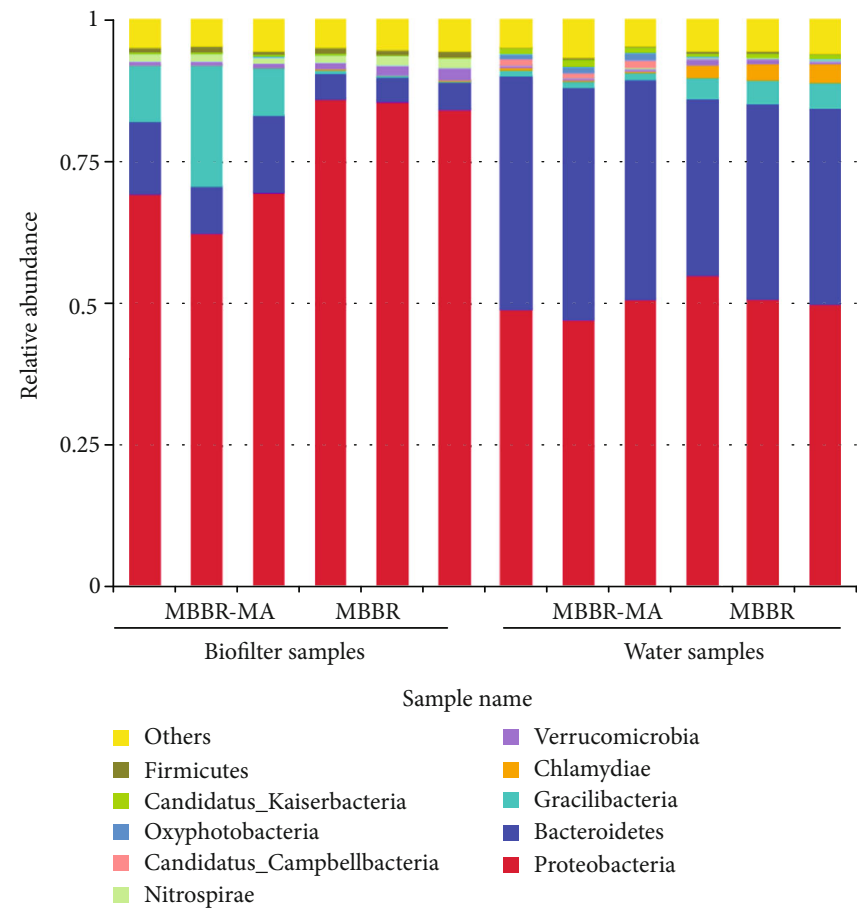

(a)

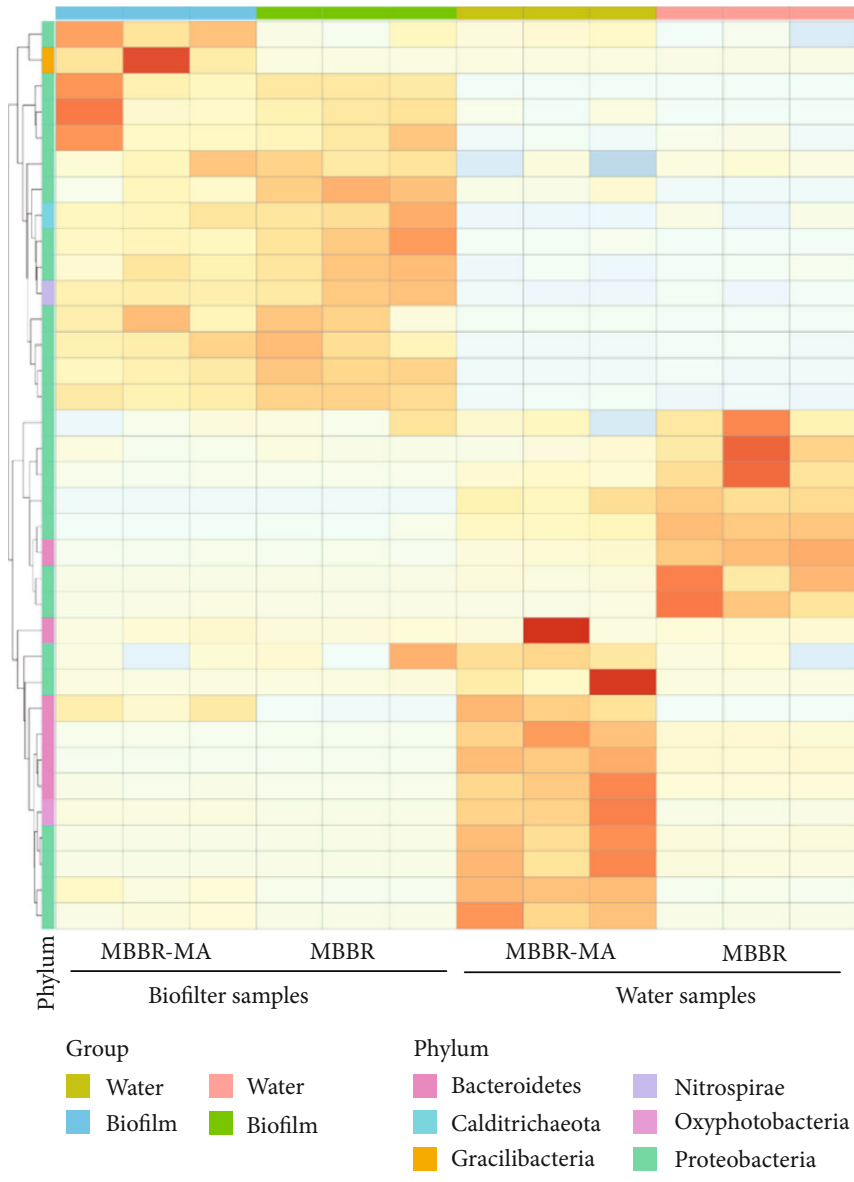

Group

Marinobacter

unidentified_Gracili

Salinimonas

Alteromonas

Sulfitobacter

Ruegeria

Marinobacterium

Calorithrix

Pseudoalteromonas

Nitrosomonas

unidentified_Nitrospiraceae

Vibrio

Halomonas

Candidatus_Thiobios

Leisingera

unidentified_Rhizobiales

Celeribacter

Marinagarivorans

Cycloclasticus

unidentified_Alphaproteobacteria

Tenacibaculum

Colwellia

unidentified_Oceanospirillales

Bacteroides

Lentibacter

Glaciecola

Kordia

unidentified_Flavobacteriaceae

Fabibacter

Crocinitomix

unidentified_Oxyphotobacteria

Pseudohongiella

Litoricola

Pseudophaeobacter

Pontivivens

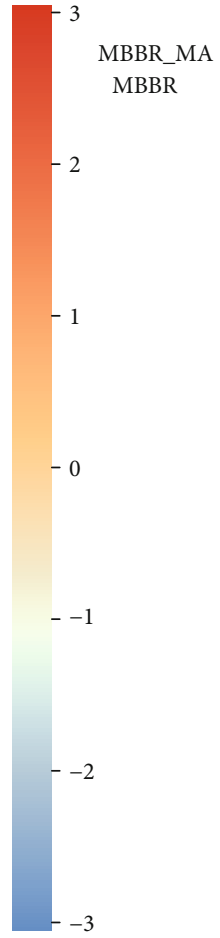

BBR_MA

(b)

Figure 5: The microbial community composition of biofilm and water samples of MBBR and MBBR-MA at the (a) phylum taxon level and (b) genus taxon level. 
bacterium, can release protease as an algicidal protein when they receive signals from algae indicating cellular senescence. On the other hand, macroalgae significantly reduced the RA of Pseudoalteromonas and Alteromonas in the MBBR-MA system compared to the MBBR system. It has been documented that members of the genus Pseudoalteromonas are involved in the formation of biofilms [52]. Bacteria belonging to the genera Pseudoalteromonas and Alteromonas produce depolymerizing enzymes and are associated with macroalgal degradation processes or algicidal activities [53, 54]. The lower abundance of those genera may be beneficial for the growth of macroalgae. Moreover, macroalgae reduced the RA of nitrifying bacteria, including Nitrosomonas $(0.49 \%$ for MBBR-MA, $0.80 \%$ for MBBR) and Nitrospiraceae (1.22\% for MBBR-MA, $1.76 \%$ for MBBR), in biofilters. The numerical dominance of NOB (i.e., Nitrospiraceae) over AOB (i.e., Nitrosomonas) might be a general characteristic of ammonium limited systems [55], which was in agreement with other studies in which the ammonia concentration was relatively low (around $2 \mathrm{mg} / \mathrm{L}$ ). Most of the dominant microorganisms in the biofilm were present at very low levels in the water samples, which reinforced the above findings of differences in microbiota between water and biofilms.

Intensive interactions were identified between bacteria and macroalgae, including stimulatory and inhibitory effects on each other by modifying the chemical microenvironment of the other group through metabolic activities $[55,56]$. Our study revealed that an MA culture integrated with an MBBR changed the microbial community in biofilters, decreasing the abundance of nitrifying bacteria and increasing the abundance of heterotrophic bacteria through the absorption of inorganic nitrogen and release of organic matter. Further research is required to determine how the integration of macroalgae influences the microbial functionality and nitrogen removal efficiency of an MBBR biofilter and to investigate the potential interactions between macroalgae and bacteria.

\section{Summary and Conclusions}

An integrated MBBR-MA circulating system was performed for both nutrient removal and macroalgae biomass production. The MA improved the TN removal efficiency of MBBR from $3.9 \%$ to $42.8 \%$, mainly by nitrate absorption, and contributed to $66.8 \%$ TP removal which enabled the sustainable operation of a marine RAS. Chaetomorpha maxima achieved a specific growth rate of $3.86-10.35 \%$ /day through nutrient recovery, and the uptake $\mathrm{N}: \mathrm{P}$ ratio by MA was 6 . Phosphorus could be a limiting factor for Chaetomorpha maxima to uptake nitrogen when the influent $\mathrm{N}: \mathrm{P}$ ratio increased. The high-throughput sequencing results revealed a shift in the microbial composition of both water and biofilter samples in the systems with and without macroalgae.

\section{Data Availability}

The data used to support the findings of this study are included within the article.

\section{Conflicts of Interest}

The authors declare that they have no known competing financial interests or personal relationships that could have appeared to influence the work reported in this paper.

\section{Authors' Contributions}

Xian Li and Yale Deng contributed equally to this work and should be considered co-first authors.

\section{Acknowledgments}

This work was supported by the National Key R\&D Program of China (2017YFD0701700), Key R\&D Program of Guangdong Province (2019B020215001), the Agricultural Application Technology Innovation Project of Shandong Province in 2018 and China Agriculture Research System (CARS-47).

\section{References}

[1] C. I. M. Martins, E. H. Eding, M. C. J. Verdegem et al., "New developments in recirculating aquaculture systems in Europe: a perspective on environmental sustainability," Aquacultural Engineering, vol. 43, no. 3, pp. 83-93, 2010.

[2] W. Jiang, X. Tian, L. Li et al., "Temporal bacterial community succession during the start-up process of biofilters in a coldfreshwater recirculating aquaculture system," Bioresource Technology, vol. 287, p. 121441, 2019.

[3] R. K. Sonwani, G. Swain, B. S. Giri, R. S. Singh, and B. N. Rai, "A novel comparative study of modified carriers in moving bed biofilm reactor for the treatment of wastewater: process optimization and kinetic study," Bioresource Technology, vol. 281, pp. 335-342, 2019.

[4] T. M. Samocha, J. S. Wilkenfeld, T. C. Morris, E. S. Correia, and T. Hanson, "Intensive raceways without water exchange analyzed for white shrimp culture," Global Aquaculture Advocate, vol. 13, pp. 22-24, 2010.

[5] J. Van Rijn and J. M. Ebeling, "Denitrification," in Recirculating Aquaculture, pp. 387-424, Cayuga Aqua Ventures, Ithaca, New York, 2010.

[6] W. Liu, H. Tan, W. Chen et al., "Pilot study on water quality regulation in a recirculating aquaculture system with suspended growth bioreactors," Aquaculture, vol. 504, pp. 396403, 2019.

[7] C. I. M. Martins, M. G. Pistrin, S. S. W. Ende, E. H. Eding, and J. A. J. Verreth, "The accumulation of substances in Recirculating Aquaculture Systems (RAS) affects embryonic and larval development in common carp Cyprinus carpio," Aquaculture, vol. 291, no. 1-2, pp. 65-73, 2009.

[8] J. Davidson, C. Good, C. Williams, and S. T. Summerfelt, "Evaluating the chronic effects of nitrate on the health and performance of post-smolt Atlantic salmon Salmo salar in freshwater recirculation aquaculture systems," Aquacultural Engineering, vol. 79, pp. 1-8, 2017.

[9] X. Yang, X. Song, L. Peng, E. Hallerman, and Z. Huang, "Effects of nitrate on aquaculture production, blood and histological markers and liver transcriptome of Oplegnathus punctatus," Aquaculture, vol. 501, pp. 387-396, 2019.

[10] A. K. Buhmann, U. Waller, B. Wecker, and J. Papenbrock, "Optimization of culturing conditions and selection of species 
for the use of halophytes as biofilter for nutrient-rich saline water," Agricultural Water Management, vol. 149, pp. 102114, 2015.

[11] J. Van Rijn, Y. Tal, and H. J. Schreier, "Denitrification in recirculating systems: theory and applications," Aquacultural Engineering, vol. 34, no. 3, pp. 364-376, 2006.

[12] Y. J. Ruan, Y. L. Deng, X. S. Guo et al., "Simultaneous ammonia and nitrate removal in an airlift reactor using poly (butylene succinate) as carbon source and biofilm carrier," Bioresource Technology, vol. 216, pp. 1004-1013, 2016.

[13] S. M. Zhu, Y. L. Deng, Y. J. Ruan, X. S. Guo, M. M. Shi, and J. Z. Shen, "Biological denitrification using poly (butylene succinate) as carbon source and biofilm carrier for recirculating aquaculture system effluent treatment," Bioresource Technology, vol. 192, pp. 603-610, 2015.

[14] U. Yogev, M. Vogler, O. Nir, J. Londong, and A. Gross, "Phosphorous recovery from a novel recirculating aquaculture system followed by its sustainable reuse as a fertilizer," The Science of the total environment, vol. 722, p. 137949, 2020.

[15] E. B. Taboada, "Simultaneous ammonium and phosphate uptake capacity of macroalage Ulva species in effluent seawater," Journal of Bioscience and Bioengineering, vol. 108, pp. S77-S78, 2009.

[16] D. Kerrigan and C. C. Suckling, "A meta-analysis of integrated multitrophic aquaculture: extractive species growth is most successful within close proximity to open-water fish farms," Reviews in Aquaculture, vol. 10, no. 3, pp. 560-572, 2018.

[17] S. Ge and P. Champagne, "Cultivation of the marine macroalgae Chaetomorpha linum in municipal wastewater for nutrient recovery and biomass production," Environmental Science \& Technology, vol. 51, no. 6, pp. 3558-3566, 2017.

[18] S. Laramore, R. Baptiste, P. S. Wills, and M. D. Hanisak, "Utilization of IMTA-produced Ulva lactuca to supplement or partially replace pelleted diets in shrimp (Litopenaeus vannamei) reared in a clear water production system," Journal of Applied Phycology, vol. 30, no. 6, pp. 3603-3610, 2018.

[19] B. V. A. S. M. Bambaranda, T. W. Tsusaka, A. Chirapart, K. R. Salin, and N. Sasaki, "Capacity of caulerpa lentillifera in the removal of fish culture effluent in a recirculating aquaculture system," Processes, vol. 7, no. 7, p. 440, 2019.

[20] K. R. Nambiar and S. D. Bokil, "Luxury uptake of nitrogen in flocculating algal-bacterial system," Water Research, vol. 15, no. 6, pp. 667-669, 1981.

[21] J. Liu, Y. Wu, C. Wu et al., "Advanced nutrient removal from surface water by a consortium of attached microalgae and bacteria: a review," Bioresource Technology, vol. 241, pp. 11271137, 2017.

[22] X. Ma, W. Zhou, Z. Fu et al., "Effect of wastewater-borne bacteria on algal growth and nutrients removal in wastewaterbased algae cultivation system," Bioresource Technology, vol. 167, pp. 8-13, 2014.

[23] S.-J. Chun, Y. Cui, C.-Y. Ahn, and H.-M. Oh, "Improving water quality using settleable microalga _Ettlia_sp. and the bacterial community in freshwater recirculating aquaculture system of_Danio rerio_,"Water Research, vol. 135, pp. 112$121,2018$.

[24] K. Brenner, L. You, and F. H. Arnold, "Engineering microbial consortia: a new frontier in synthetic biology," Trends in Biotechnology, vol. 26, no. 9, pp. 483-489, 2008.
[25] X. Li, X. Li, J. Wang et al., "Removal efficiency of nitrogen salts by Chaetomorpha maxima in aquacultural wastewater," Trans. CSAE, vol. 35, no. 24, 2019.

[26] Y. Zhang, J. Chen, J. Shen, S. Hou, Y. Liu, and Y. Liu, “A study on transformation of main pollutants along the wastewater flow in biological aerated filter," China Environmental Science, vol. 31, no. 11, pp. 1808-1814, 2011.

[27] M. Li, Z. Liang, M. D. Callier et al., "Nutrients removal and substrate enzyme activities in vertical subsurface flow constructed wetlands for mariculture wastewater treatment: effects of ammonia nitrogen loading rates and salinity levels," Marine Pollution Bulletin, vol. 131, pp. 142-150, 2018.

[28] M. Martin, "Cutadapt removes adapter sequences from highthroughput sequencing reads," EMBnet.journal, vol. 17, no. 1, pp. 10-12, 2011.

[29] R. C. Edgar, B. J. Haas, J. C. Clemente, C. Quince, and R. Knight, "UCHIME improves sensitivity and speed of chimera detection," Bioinformatics, vol. 27, no. 16, pp. 21942200, 2011.

[30] R. C. Edgar, "UPARSE: highly accurate OTU sequences from microbial amplicon reads," Nature Methods, vol. 10, no. 10, pp. 996-998, 2013.

[31] Q. Wang, G. M. Garrity, J. M. Tiedje, and J. R. Cole, "Naïve Bayesian classifier for rapid assignment of rRNA sequences into the new bacterial taxonomy," Applied and Environmental Microbiology, vol. 73, no. 16, pp. 5261-5267, 2007.

[32] C. Quast, E. Pruesse, P. Yilmaz et al., "The SILVA ribosomal RNA gene database project: improved data processing and web-based tools," Nucleic Acids Research, vol. 41, no. D1, pp. D590-D596, 2012.

[33] Z. Chen, S. Shao, Y. He et al., "Nutrients removal from piggery wastewater coupled to lipid production by a newly isolated self-flocculating microalga _Desmodesmus_sp. PW1," Bioresource Technology, vol. 302, p. 122806, 2020.

[34] N. Arumugam, S. Chelliapan, H. Kamyab, S. Thirugnana, N. Othman, and N. Nasri, "Treatment of wastewater using seaweed: a review," International Journal of Environmental Research and Public Health, vol. 15, no. 12, p. 2851, 2018.

[35] S. T. Larned, "Nitrogen- versus phosphorus-limited growth and sources of nutrients for coral reef macroalgae," Marine Biology, vol. 132, no. 3, pp. 409-421, 1998.

[36] S. A. Lavania-Baloo, M. I. M. Said, F. Ahmad, and M. Mohamad, "Biofiltration potential of macroalgae for ammonium removal in outdoor tank shrimp wastewater recirculation system," Biomass \& Bioenergy, vol. 66, no. 7, pp. $103-$ 109,2014

[37] P. Tsagkamilis, D. Danielidis, M. J. Dring, and C. Katsaros, "Removal of phosphate by the green seaweed Ulva lactuca in a small-scale sewage treatment plant (Ios Island, Aegean Sea, Greece)," Journal of Applied Phycology, vol. 22, no. 3, pp. 331-339, 2010.

[38] E. Marinho-Soriano, R. A. Panucci, M. A. A. Carneiro, and D. C. Pereira, "Evaluation of Gracilaria caudata J. Agardh for bioremediation of nutrients from shrimp farming wastewater," Bioresource Technology, vol. 100, no. 24, pp. 6192-6198, 2009.

[39] J. W. Costerton, Z. Lewandowski, D. E. Caldwell, D. R. Korber, and H. M. Lappin-Scott, "Microbial biofilms," Annual Review of Microbiology, vol. 49, no. 1, pp. 711-745, 1995. 
[40] O. E. Petrova and K. Sauer, "Sticky situations: key components that control bacterial surface attachment," Journal of Bacteriology, vol. 194, no. 10, pp. 2413-2425, 2012.

[41] J. P. Blancheton, K. J. K. Attramadal, L. Michaud, E. R. d'Orbcastel, and O. Vadstein, "Insight into bacterial population in aquaculture systems and its implication," Aquacultural Engineering, vol. 53, pp. 30-39, 2013.

[42] H. Hirata, S. Yamasaki, H. Maenosono, T. Nakazono, T. Yamauchi, and M. Matsuda, "Relative budgets of $p \mathrm{O}_{2}$ and $p \mathrm{CO}_{2}$ in cage polycultured Red Sea bream, Pagrus major and sterile Ulva sp.," Suisanzoshoku, vol. 42, pp. 377-381, 1994.

[43] L. C. Rai, H. D. Kumar, F. H. Mohn, and C. J. Soeder, "Services of algae to the environment," Journal of Microbiology and Biotechnology, vol. 10, pp. 119-136, 2000.

[44] X. Y. Shen, L. M. Zhang, J. P. Shen, L. H. Li, C. L. Yuan, and J. Z. He, "Nitrogen loading levels affect abundance and composition of soil ammonia oxidizing prokaryotes in semiarid temperate grassland," Journal of Soils and Sediments, vol. 11, no. 7, pp. 1243-1252, 2011.

[45] D.-E. Lee, J. Lee, Y.-M. Kim, J.-I. Myeong, and K.-H. Kim, "Uncultured bacterial diversity in a seawater recirculating aquaculture system revealed by $16 \mathrm{~S}$ rRNA gene amplicon sequencing," Journal of Microbiology, vol. 54, no. 4, pp. 296304, 2016.

[46] D. Woebken, B. M. Fuchs, M. M. M. Kuypers, and R. Amann, "Potential interactions of particle-associated anammox bacteria with bacterial and archaeal partners in the Namibian upwelling system," Applied and Environmental Microbiology, vol. 73, no. 14, pp. 4648-4657, 2007.

[47] K. Kersters, P. D. Vos, M. Gillis, J. Swings, and E. Stackebrandt, Introduction to the Proteobacteria, The Prokaryotes, New York, America, 2006.

[48] M. K. H. Winkler, Q. H. Le, and E. I. P. Volcke, "Influence of partial denitrification and mixotrophic growth of NOB on microbial distribution in aerobic granular sludge," Environmental Science \& Technology, vol. 49, no. 18, pp. 1100311010, 2015.

[49] M. Bauer, M. Kube, H. Teeling et al., "Whole genome analysis of the marine Bacteroidetes 'Gramella forsetii' reveals adaptations to degradation of polymeric organic matter," Environmental Microbiology, vol. 8, no. 12, pp. 2201-2213, 2006.

[50] D. Chen, H. Wang, K. Yang, and F. Ma, "Performance and microbial communities in a combined bioelectrochemical and sulfur autotrophic denitrification system at low temperature," Chemosphere, vol. 193, pp. 337-342, 2018.

[51] C. Paul and G. Pohnert, "Interactions of the algicidal bacterium Kordia algicida with diatoms: regulated protease excretion for specific algal lysis," Plos One, vol. 6, no. 6, article e21032, 2011.

[52] J. Bowman, "Bioactive compound synthetic capacity and ecological significance of marine bacterial genus Pseudoalteromonas," Marine Drugs, vol. 5, no. 4, pp. 220-241, 2007.

[53] S. Egan, N. D. Fernandes, V. Kumar, M. Gardiner, and T. Thomas, "Bacterial pathogens, virulence mechanism and host defence in marine macroalgae," Environmental Microbiology, vol. 16, no. 4, pp. 925-938, 2014.

[54] F. Goecke, A. Labes, J. Wiese, and J. F. Imhoff, "Chemical interactions between marine macroalgae and bacteria," Marine Ecology Progress Series, vol. 409, pp. 267-299, 2010.
[55] B. U. Foesel, A. Gieseke, C. Schwermer et al., "Nitrosomonas Nm143-like ammonia oxidizers and Nitrospira marina-like nitrite oxidizers dominate the nitrifier community in a marine aquaculture biofilm," Fems Microbiology Ecology, vol. 63, no. 2, pp. 192-204, 2008.

[56] J. A. Hargreaves, "Photosynthetic suspended-growth systems in aquaculture," Aquacultural Engineering, vol. 34, no. 3, pp. 344-363, 2006. 